\title{
Eruption trials
}

\author{
The eruption of Mount Tambora in 1815 has been linked to climate change and social unrest. Such \\ historical eruptions could serve as test cases for models used to assess future climate changes.
}

The summer of 1816 was freakishly cold for parts of North America and Europe, with frequent frosts, excessive rainfall and even some snow. The writer Mary Shelley and friends had travelled to Switzerland for a summer holiday, only to spend most of the trip snuggled up in a chalet, hiding away from the harsh weather. Supposedly, a competition among the party to write the best ghost story led to the creation of Frankenstein. The severe conditions, and thus incidental creative inspiration for Shelley's classic tale, were caused by a giant eruption in Indonesia - that of Tambora in the previous year ${ }^{1}$. Yet most people in Europe were unaware of any eruption. At the time, the links between volcanic activity and climate change were not widely appreciated. A web focus linked to this issue (http://www.nature. com/ngeo/focus/tambora-eruption/index.

html) brings together a series of articles that discuss the lessons learnt from the Tambora eruption, two hundred years on.

The impact of Tambora's eruption on the atmosphere is also thought to have inspired artists such as William Turner and Caspar David Friedrich. Ash hanging in the atmosphere would have scattered the Sun's rays, creating rich red sunsets that could have led to the creation of some of the early nineteenth century's greatest landscape paintings ${ }^{1}$. But any positive influences from Tambora, no matter how tentative, seem to stop here. In the immediate aftermath of the eruption, thousands of people in Indonesia were killed. And in the coming years, many thousands more across the world were indirectly affected as the volcanic gases and ash gradually wrapped the globe, cooling the atmosphere. In parts of Europe, North America and Asia, crops failed, grain prices rose and famines spread.

Of course, the famines probably weren't the result of volcanism-induced climate change alone. As Oppenheimer argues on page 244, many regions strongly affected by the cool weather and crop failures were already experiencing severe famine and social unrest in the wake of the Napoleonic wars the climatic shift simply exacerbated existing problems. The Tambora eruption also came on the heels of a prolonged period of cooler temperatures known as the Little Ice Age. The early 1800 s were particularly cold - even in the tropics ${ }^{2}-$ as a consequence of the

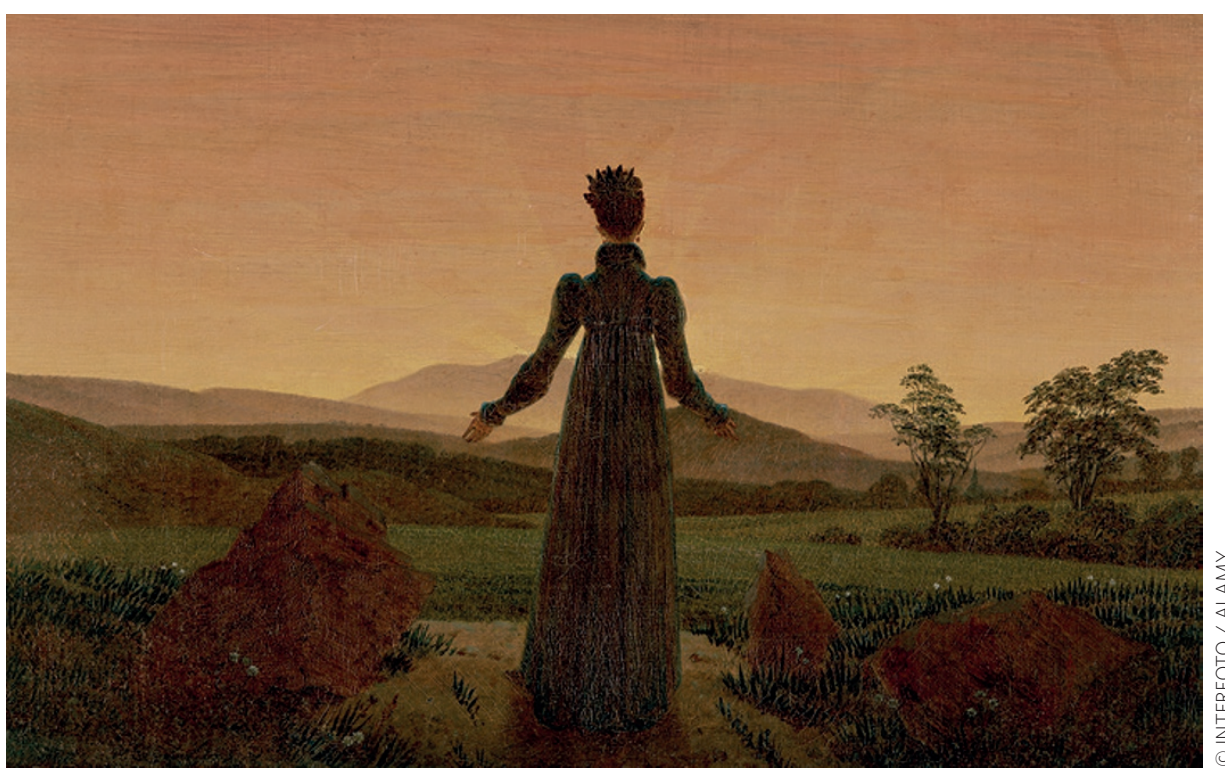

unusually low solar activity of the Dalton minimum and previous eruptions, such as that of Laki in Iceland in 1783 and a tropical eruption in 1809.

We do not know when the world might again face a Tambora-scale eruption (page 248). However, the ongoing remote and in situ monitoring of volcanoes worldwide should provide some warning of an impending event and our understanding of the climatic impacts of individual eruptions is continuously growing ${ }^{3}$ (and see page 251) For example, on page 243 Gettelman and colleagues calculate the radiative effects of sulphur-rich gases that have been erupting from two volcanic fissures in Iceland since August 2014 in near-real time.

Such short-lived changes in stratospheric aerosol content linked to eruptions can serve as test cases for models attempting to assess the effects of future changes in radiative forcing due to anthropogenic emissions. So far, the results of such tests are mixed. Many current-generation models indicate varying responses to known eruptions during the last millennium, such as eruptions in AD 1258, 1453, and of course Tambora ${ }^{4}$.

Part of this apparent mismatch between proxy reconstructions of volcanic cooling and model simulations could reflect spatial variations in temperature responses to eruptions. As Luterbacher and Pfister point out on page 246 , the climatic effects of the
Tambora eruption varied widely across Europe. Such local-scale variations might not be picked up in proxy compilations that are averaged across an entire continent or latitudinal band, leading to a disagreement when model simulations and proxy records are compared. Uncertainties in the height of the eruption column and the magnitude of stratospheric sulphur release also hinder accurate simulations, and at least some of the problem reconciling temperature records and simulations probably results from uncertainties in our understanding of the climate response to abrupt changes in radiative forcing

Nonetheless, current climate models urgently require robust testing ${ }^{5}$ and we have at our disposal the means for such assessments. Historical volcanic eruptions provide distinct pulses of radiative forcing in an otherwise equable Holocene climate a great testing ground for deepening our understanding of climate change and its impact of society.

\section{References}

1. Wood, G. D. A. Tambora: the Eruption that Changed the World (Princeton Univ. Press, 2014)

2. Tierney, J. et al. Paleoceanography http://dx.doi. org/10.1002/2014PA002717 (2015).

3. Schmidt, A., Fristad, K. E. \& Elkins-Tanton, L. T. (eds) Volcanism and Global Environmental Change (Cambridge Univ. Press, 2015).

4. D’Arrigo, R., Wilson, P. \& Anchukaitis, K. J. J. Geophys. Res. Atmos. 118, 9000-9010 (2013).

5. Valdes, P. Nature Geosci. 4, 414-416 (2011). 